\title{
The Constitution of Non-Monetary Surplus Values
}

vB

"The value of commodities that is valorizing itself, always striving for its own increase, is
the 'automatic subject' of society, constituted by human beings by their daily actions, but
at the same time subjecting them totally and making them mere functionaries of an
anonymous, unconscious process that is out of their control."

This is a quotation from Klaus Kempter's contribution to this symposium. In style and terminology, it is written in the tradition of Karl Marx, but in its substance, it is not far away from Niklas Luhmann: profit, i.e. the institutionalized pressure to create surplus value, is the anonymous self-regulating principle of the recursive autopoietic selfmovement of the economic system - but not only of the economy. This is a decisive difference. The renewed Marxist Wertkritik claims to capture the totality of modern societies. But this is a mistaken totalization of economic value and monetary profit. It ignores the development of social theory after Karl Marx, from Max Weber to Pierre Bourdieu.

What follows are six arguments which rebut the primacy of economic profit in advanced capitalist societies, and submit that the imperative to create surplus value is a function of autopoietic systems generally and not merely a product of economic forces. As a consequence, the critique of capitalist society would no longer solely be directed at surplus value compulsion within the economy. Nor would it only challenge the increasing economization of social worlds, i.e. the expansion, pushed by neo-liberal fanatics, of the economic profit principle into non-economic areas of society, which threatens all social activities to produce monetary profit or else be done away with completely. Rather, a more profound critique would have to deal with a different kind of society-wide expansion of the capitalist logic. My thesis is: Apart from economic profit, a multiplicity of non-monetary surplus value pressures are responsible for capitalism's productive dynamics, in particular for its destructive effects.

\section{Argument \# 1: Generalization and respecification of surplus value:}

Not only the economy but also other functional systems force each of their operations to generate a specific surplus value-but now explicitly non-monetary-beyond its immediate production of meaning. Bourdieu's theory of social fields has generalized Marx' category of capital and respecified different types of capital in various social fields. The same generalization and respecification needs to be done in regard to the category of profit, or surplus value, to allow identification of different types of surplus value production in various social fields. In politics, for example, non-monetary surplus value means that each policy-decision needs to generate simultaneously a surplus of political power for future use. In science, successful research in the various subject 
areas, oriented towards the production of knowledge, includes the imperative to surplus in the form of reputational gain. In law, the courts are under the pressure to produce a normative surplus value, i.e. a specific persuasive authority that can be generalized for the future, over and above the concrete resolution of the immediate dispute.

\section{Argument \# 2: Object of surplus value orientation:}

Functional systems expend energy constantly to regenerate and to augment their own communication medium beyond the actual result of production. It is the surplus of the system's own communication medium - power, truth/reputation, money, normativity, style, faith - which is produced via the reflexive application of operations to further operations. In this reflexive process, not only are the usual follow-up operations made possible, but at the same time the ability to operate is restored or even increased. Moreover, if this is established as a criterion of self-regulation, then the various surplus pressures become the driving dynamics of the expansion imperatives in modern society. Maximizing output misses the point: augmentation of its medium of communication is the dominant pressure on each activity.

\section{Argument \# 3: Why communication medium?}

The special contribution of communication media consists in creating the motives for accepting a communication, overcoming outright resistance. Why should one accept highly improbable assertions of learned scholars? Why obey inconvenient commands of self-proclaimed leaders? Why follow norms that are not in one's own interest? Why accept claims to exclusive ownership? Communication media are success-media (in contrast to dissemination-media such as orality, writing, printing, digitality) insofar as they exert an almost irresistible motivational force, which makes the acceptance of a communication highly probable in cases in which rejection is likely. The overwhelming motivational power of communication media is the driving motor for the dynamics of capitalist societies. And the turbocharger is surplus value orientation. Constantly augmenting the motivational force of the specialized communication medium accelerates immensely the internal dynamics of several functional systems. Values as such are not responsible for the acceleration, they are rules of preference that give only direction to processes. The very acceleration occurs when pressures toward the surplus of values are created.

\section{Argument \# 4: Surplus value orientation is a non-individual anonymous matrix:}

The motivational power of communication media is not to be identified with mental states of individuals. Instead, firmly institutionalized social processes are oriented toward surplus value production with units of success that measure achievement whether or not they are accompanied by individual greed for power, money or reputation. What 'really motivates' individual persons is not the same as the systemic 
motive established by the communication medium, which is the primary target of socially established surplus orientation. There is a clear division between psychic and social processes and each of them is accountable for the creation of meaning in its own right. This separation of communicative processes in society and psychic processes in individual consciousness is crucial to grasping the dynamics of surplus value orientation. But there is an elective affinity between psychic processes and social structures, between individual greed and social surplus pressures. After all, hedge funds fascinate and attract greedy personalities. The multiple surplus pressures are Max Weber's "iron cages of the slavery of the future", in which individuals are trapped.

\section{Argument \# 5: Excessive ambivalence:}

The success of surplus pressures is responsible for the immensely productive forces unleashed in capitalism. They demonstrate an excessive ambivalence: immense productivity and its destructive dark side. Like the monetary profit pressure in the economy, the non-monetary surplus pressures have their ugly faces, too. The destructive and self-destructive tendencies, rightly attributed by Marx to relentless profit maximization in the economy, have multiplied in non-monetary surplus pressures of other areas of life, which are working with no less force. The growing discrepancy between the productive success of the communication medium and its destructive effects leads to all kinds of dysfunctionalities. Within each social system, in politics, the economy, law, science and technology, ruthless surplus value maximization becomes almost a collective addiction, i.e. the repetition and multiplication of a self-damaging social behavior despite the keen knowledge of its harmful effects. And in their external relations, the systems' colonizing expansion extracts its specific surplus value from other domains of society. Processes of global economization, politicization, scientification, juridification take place, even simultaneously, with disastrous consequences for the ecology in the broadest sense, i.e. for the natural world, for society and for individuals.

\section{Argument \# 6: Counter-strategies:}

How should constitutions deal with the excessive ambivalence of ubiquitous surplus value production? Surplus restrictions? Changes to profit distribution? Collectivization of the non-monetary generation of profit? Liberation from societal pressure towards profit maximization? If it is true that the compulsion to siphon off surplus value is structurally rooted everywhere throughout the whole society, albeit in different forms, then it is no longer sufficient to make a constitutional decision for or against a profitdriven economy. Hopes for the abolition of private property and the elimination of the monetary profit orientation are in vain. The destructive tendencies of non-monetary surplus value maximization in other systems, especially in science, technology, law and, of course, politics, would remain completely unaffected.

The way constitutions deal with diverse societal surplus productions would have to be conceived more carefully than any simple prohibition strategy would do. Inspiration could come from a reformulation of Karl Polanyi's famous double movement, from the 
history of the economy's disembedding and its re-embedding. The most fascinating elements of Karl Polanyi's theory are the three false (or fictitious) commodities and what he calls non-market modes of economic integration. False commodities - land, labor, and money - are for Polanyi the sites where monetary surplus production runs up against the reality of collective political actors. For Polanyi, labour unions and central banks were the new collective institutions that tended to counteract the economy's disembedding.

Now, can one identify equivalents to false commodities in social areas which are driven by non-monetary surplus orientation? False surplus pressures - that would be the equivalent obstructing the public interest. To identify them would reveal the sites where the agonistic relation between surplus orientation and democratic egalitarianism leads to unresolvable conflicts. The challenge for the future would be to identify false surplus pressure in the various social domains. Institutional imagination would be needed to replace them by non-surplus institutions. In politics, the great historical example has been minorities which had been repressed in a regime based on false pressures for power surplus. As a response, constitutional courts, i.e non-majoritarian institutions which are relatively independent from power politics, have advanced constitutional rights for minority protection. In the future, "horizontal" constitutional rights could play a decisive role when false surplus pressures violate the integrity of individual life or institutional dynamics in the digital world, in economic organizations, in the news media and in other social domains. Particularly, in science and medicine, where new biotechnological developments increase surplus pressures that threaten human patients' and animals' interests, non-surplus oriented institutions would counteract the combined pressures of professional reputation and economic profit. A promising example is ICANN, the governance of the internet, which attempts to counteract the combined surplus pressures from economic, technological, scientific and political interests. ICANN does so by transforming itself into a non-profit and non-state organization which is legitimized by a stakeholder constitution. 


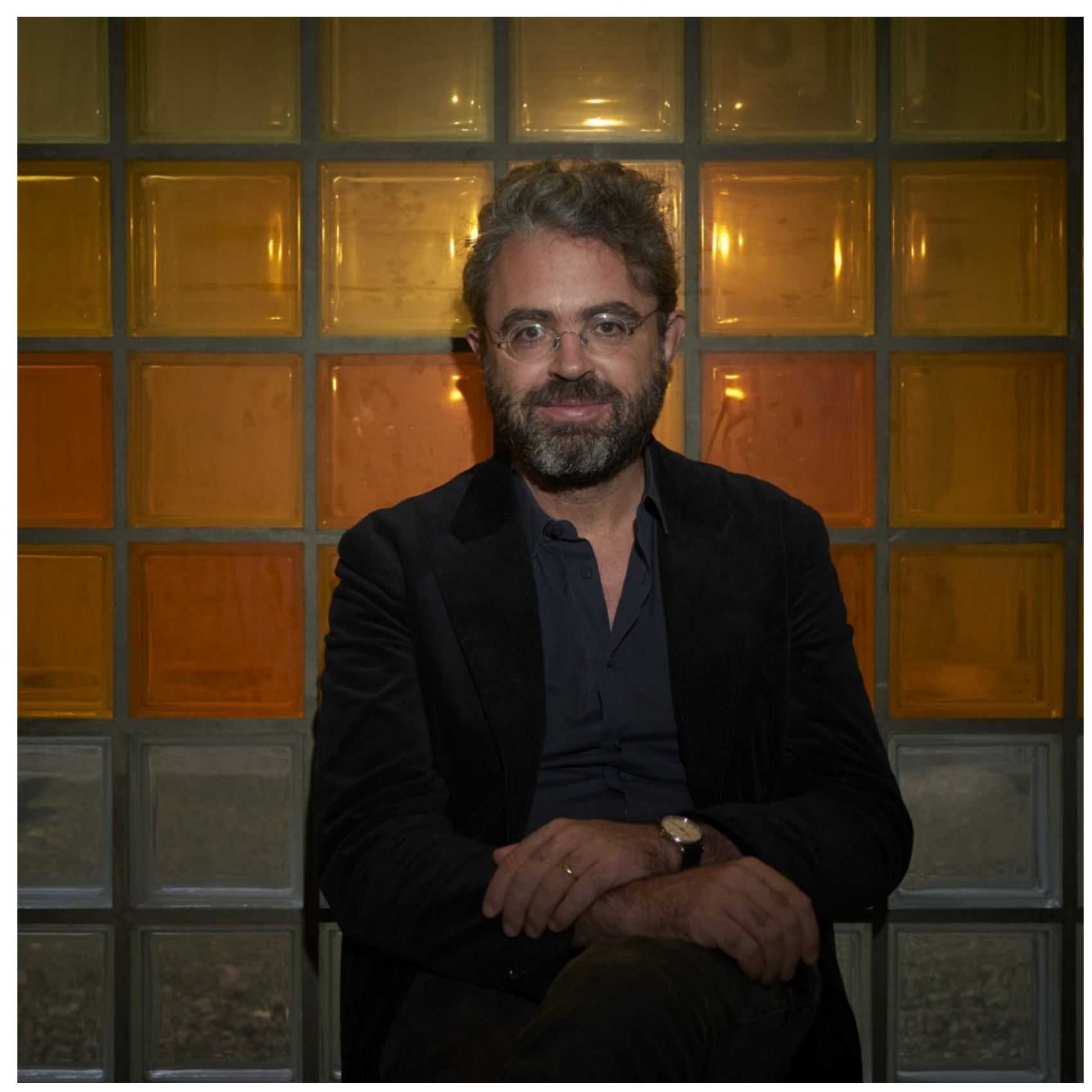

\section{While you are here...}

If you enjoyed reading this post - would you consider supporting our work? Just click here. Thanks!

All the best, Max Steinbeis

SUGGESTED CITATION Teubner, Gunther: The Constitution of Non-Monetary Surplus Values, VerfBlog, 2020/3/o3, https://verfassungsblog.de/the-constitution-ofnon-monetary-surplus-values/, DOI: https://doi.org/10.17176/20200303-094612-0. LICENSED UNDER CC BY NC ND 